University of Rhode Island

DigitalCommons@URI

Open Access Master's Theses

1995

\title{
Personality Type and Medical Specialty Choice
}

Ann M. Ronan

University of Rhode Island

Follow this and additional works at: https://digitalcommons.uri.edu/theses

\section{Recommended Citation}

Ronan, Ann M., "Personality Type and Medical Specialty Choice" (1995). Open Access Master's Theses.

Paper 1699.

https://digitalcommons.uri.edu/theses/1699

This Thesis is brought to you for free and open access by DigitalCommons@URI. It has been accepted for inclusion in Open Access Master's Theses by an authorized administrator of DigitalCommons@URI. For more information, please contact digitalcommons-group@uri.edu. 
RF695

R6e

$\because ?$

PERSONALITY TYPE AND MEDICAL SPECIALTY CHOICE

BY

ANN M. RONAN

A THESIS SUBMITTED IN PARTIAL FULFILLMENT OF THE

REQUIREMENTS FOR THE DEGREE OF

MASTER OF ARTS

IN

ADULT EDUCATION

340686

UNIVERSITY OF RHODE ISLAND

1995 


\begin{abstract}
The association between personality type and residency specialty choice was investigated with a sample of 220 medical students. Personality type was determined by the Myers-Briggs Type Indicator and residency specialty choice was divided into two categories: primary care and subspecialties. The results indicated that 1) the perceiving types chose subspecialties and judging types chose primary care more often than expected (p. <.01), 2) intuitive/thinking types chose subspecialities and sensing/thinking, sensing/feeling, and intuitive/feeling types chose primary care more often than expected (p<.01), and 3) sensing/judging types chose primary care and sensing/perceiving types chose subspecialties more often than expected $(\mathrm{p}<.001)$. The findings are consistent with the literature and support Myers-Briggs' theories. It is recommended that career counselors in medical schools use the Myers-Briggs Indicator in assisting students with specialty choice decisions.
\end{abstract}




\section{ACKNOWLEDGMENTS}

I am grateful for the assistance and encouragement I received from William Hooker, Ph.D., Loma Linda University, School of Dentistry, Timothy Neufeld, M.D., Loma Linda University, School of Medicine, Department of Family Medicine, and Kelly Morton, Ph.D., Loma Linda University, School of Medicine, Department of Family Medicine. 


\section{TABLE OF CONTENTS}

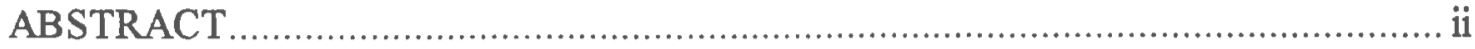

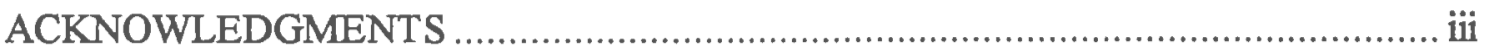

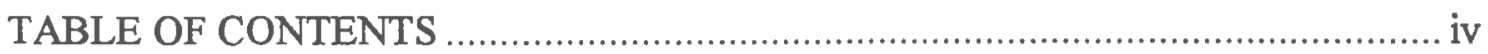

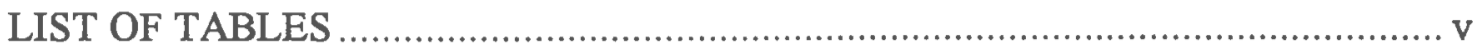

Chapter

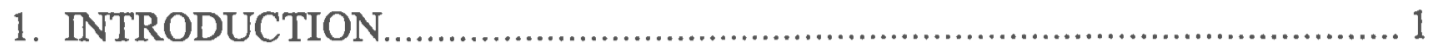

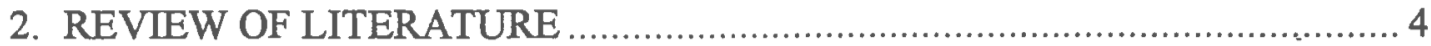

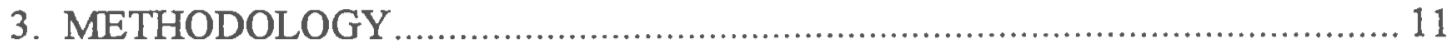

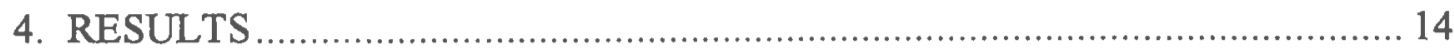

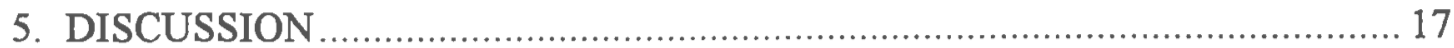

6. SUMMARY, CONCLUSIONS, AND RECOMMENDATIONS …................... 21

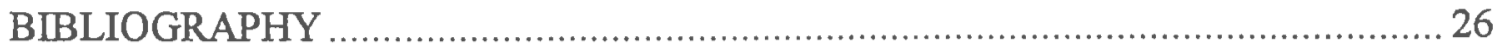




\section{LIST OF TABLES}

Table

Page

1. Perceiving/Judging Dimensions and Specialty Choice................................... 15

2. Information-Gathering/Decision-Making Dimensions

and Specialty Choice 16

3. Temperament Type and Specialty Choice. 16 


\section{CHAPTER 1}

\section{INTRODUCTION}

The purpose of this study was to determine whether there are differences in the psychological type of Loma Linda University medical students who choose primary care rather than subspecialty residencies.

According to the American Association of Medical Colleges (AAMC), the number of primary care physicians entering practice in the United States has declined markedly over the past several years (Petersdorf, 1993). Robert G. Petersdorf, M.D., President of the AAMC, cites AAMC data showing that the number of senior medical students expressing interest in primary care specialties has declined from $36.1 \%$ in 1982 to $14.6 \%$ in 1992 (Petersdorf, 1993).

This decline in the number of primary care physicians is occurring at a time when the nation is reviewing its health care system. With the expansion of managed care, more primary care physicians are needed to provide cost-effective, accessible health care (Greer, Bhak, \& Zenker, 1994). The Clinton Health Security Act proposed increasing the number of primary care physicians practicing in the United States to $50 \%$. Moreover, $32 \%$ of United States physicians provide primary care compared to $50 \%$ in other developed industrialized countries (Petersdorf, 1993). This goal would have been accomplished by increasing the number of primary care residency positions and by increasing funding to these programs (The President's Health Security Plan, 1993). 
While politicians attempted to work out a national health care system, insurance companies rapidly changed the way they do business with health care providers (Alper, 1994, Iglehart, 1994). These changes occurred in the areas of patient access to physicians, finances, and day-to-day practice.

Patients cannot always choose their physician: in managed care systems, patients choose a primary care physician from within the groups the insurers have contracts with. In addition, patients cannot see a specialist without first seeing a primary care physician who provides referrals to specialists, if deemed appropriate. This system has increased the need for primary care physicians.

In the area of finance, the traditional "fee for service" type payment is being replaced by a "capitation" payment system: a physician, or more often, a practice group or medical corporation, agrees to enroll a certain number of the insurers patients for a set annual fee per patient - regardless of the number of patient visits or types of medical problems treated. This change has forced many physicians to acquire business acumen and marketing skills in order to thrive financially.

Managed care systems also change the fundamental ways a physician practices medicine. There are a number of rules and requirements set forth by the insurance companies that must be followed. For example, certain drugs may not be covered by an insurance company, requests for many lab tests and procedures must be approved by a utilization review employee, and standard of care guidelines are set by the insurance company and must be followed (Iglehart, 1994). 
These changes in the way physicians must practice may attract different personality types to the primary care arena than was seen in the past. Personality types who prefer working in a structured organization would be attracted to the managed care environment, while personality types who prefer more flexibility may bristle under the many rules and requirements. The thinking types would be able to analyze patient problems with impersonal logic, while the feeling types would face difficult decisions weighing patients's needs against financial realities.

The AAMC offers recommendations to increase the number of students choosing primary care careers. One of the suggestions is to "initiate studies to elucidate further the most influential factors responsible for the career choices of medical students and residents" (AAMC Policy Statement, 1993, p. 3). Another recommendation is to "identify and nurture interest in generalism among applicants and matriculants to medical school" (AAMC Policy Statement, 1993, p. 2).

This study responds to both of these recommendations. It could be the beginning of a tracking system to determine which Loma Linda University students enter primary care careers, and if personality type, as measured by the Myers Briggs Type Indicator (MBTI), predicts students' choice of primary care specialties. If it is found that students with certain personality types are more likely to choose primary care careers, career counselors could use the MBTI in counseling these students about potential career options in primary care. 


\section{CHAPTER 2}

\section{REVIEW OF LITERATURE}

A number of studies (Mitchell, 1975; Otis \& Weiss, 1973; Weil \& Schleiter, 1981;

Zeldow \& Daugherty, 1991 ) have been reported in the medical literature regarding factors that affect specialty choice. Such factors include economics, gender, and religious background, but one of the more provocative is the relationship between personality and career choice.

Weil \& Schleiter (1981) found that background variables (e.g. childhood environment and religious affiliation) and personal variables (including personality type) are more predictive than environmental variables such as the type of medical school a student attends in predicting preference for primary care or subspecialty care. Zeldow and Daughterty (1991) suggest that there is a need to reexamine the role of personalty in specialty choice because of changes in the knowledge bases, public images, and modes of practice in the specialties.

\section{Myers-Briggs Type Indicator}

The Myers-Briggs Type Indicator (MBTI) is an instrument used to measure personality type. The MBTI was developed by Kathleen Myers and her daughter Isabel Briggs Myers as a means of implementing C.G. Jung's theory of psychological type which focuses on the conscious direction of perception and judgment. According to Myers \& 
McCaulley, perception is the process of "becoming aware of things, people, happenings, or ideas" (Myers \& McCaulley, 1985, p.1). Judgment is the process of "coming to conclusions about what has been perceived." (Myers \& McCaulley, 1985, p.1).

The MBTI classifies people into one of sixteen types based on how one perceives the world and makes decisions about what is perceived. The Inventory uses four bipolar scales: Extraversion (E) versus Introversion (I) measures one's preferred source, direction, and focus for energy. Extraverts are gregarious, enthusiastic, and initiating, while introverts are intimate, quiet, and contained;

Sensing (S) versus Intuition $(\mathrm{N})$ measures one's preferred manner of gathering information. Sensors prefer to gather information using their senses. They are described as concrete, realistic, and pragmatic. Intuitives grasp possible meanings and connections in the data they gather. They are described as abstract, imaginative, and intellectual;

Thinking $(T)$ versus Feeling $(F)$ measures one's preferred decision-making style. Thinkers prefer logical and fair decisions. They are described as critical, tough, and logical. Feelers make decisions based on their value systems. They are described as accepting, tender, and accommodating;

Judgment (J) versus Perception (P) measures one's preferred use of either the Sensing/Intuitive (gathering data) function or the Thinking/Feeling (decision-making) function in relating to the external world. Judgers spend less time gathering data and move quickly to decision-making while perceivers spend more time exploring options and delay making decisions. Judgers are described as stress avoiders, systematic, and 
scheduled. Perceivers are described as spontaneous, casual, and open-ended. (Myers \& McCaulley, 1985).

The MBTI is a useful instrument for predicting type preferences for different occupations in medicine (Myers \& McCaulley, 1977; Friedman and Slatt, 1988). The MBTI indicates an individual's interests and the types of activities that would motivate and satisfy in a career (Myers \& McCaulley, 1985). Research shows that the sensing/intuitive and thinking/feeling functions are the most significant when choosing an occupational field while the extraverted/introverted and judging/perceiving attitudes are useful in selecting a working environment or specific organization within a field (Career Report Manual, 1992).

\section{Keirsey \& Bates Temperament Theory}

David Keirsey and Marilyn Bates (Keirsey \& Bates, 1978) used the Myers-Briggs Type Indicator as a springboard for developing their temperament theory. They define temperament as the driving force behind our behavior - the signature on each of one's actions making it recognizably our own (Keirsey \& Bates, 1978).

Keirsey and Bates defined four temperaments, SP, SJ, NT, and NF, based on Jung's \& Myers-Briggs' work. They named four Greek gods to represent the four temperaments: Dionysus (SP), Epimetheus (SJ), Prometheus (NT), and Apollo (NF). They outlined the following motivations and career preferences of the four types:

SP's are represented by Dionysus, the god of joy. They are driven by the instinct for pleasure. They focus on the present, hunger for action, and thrive in situations where the 
outcome is not known; therefore, they deal well with crisis situations. They also like to work with tools. They are attracted to careers that provide variety and action: military positions, performing arts, and athletics are some of the areas in which they excel.

SJ's are represented by Epimetheus, the god of duty. They are driven by the security of social status. They must be useful, and are compelled to be bound and obligated. They tend to work within institutions, establishing them, nurturing them, and maintaining them. According to Keirsey \& Bates, they would be attracted to medicine and rehabilitating.

NT's are represented by Prometheus, the god of science. They are driven by the desire for power: "...not power over people, but power over nature" (Keirsey \& Bates, 1978, p.48). They need to understand and control nature, must feel competent, and are self-critical. They are attracted to the sciences and technology: fields that are complicated and exacting. They excel in engineering, architecture, philosophy, and mathematics.

The NF's are represented by Apollo, the god of spirit. They seek self-actualization. They strive to be authentic and want their unique contributions to be recognized. They enjoy working with people and prefer to focus on relationships. They are attracted to psychiatry, missionary work, teaching, and writing.

\section{Differences Between Specialties}

Primary care physicians assume longitudinal responsibility for their patients and provide comprehensive, continuous care. They approach patients with a whole-person focus and retain the coordinating role when specialists are involved. Primary care physicians must often make a diagnosis before the full clinical picture has developed. 
They possess breadth of knowledge across all ages, organs and systems. They deal with a variety of situations in a typical day. There are three primary care specialities: family medicine, general internal medicine and pediatrics (AAMC Policy Statement, 1993).

Subspecialists most often provide episodic care rather than continuous and comprehensive care. They usually approach patients with a disease-oriented emphasis rather than a whole-person focus. They see diseases in the later stage, often after a diagnosis has been made by a primary care physician. The subspecialist's knowledge is one of depth rather than breadth, and the types of problems they will see in a typical day are more defined and contain less variety than those seen by a primary care physician.

\section{Use of MBTI in Primary Care Research}

Previous research using the MBTI in medical education investigated the personality types of students who chose primary care specialties (Friedman and Slatt, 1988; Myers and McCaulley, 1977; Quenk and Heffron, 1975; Taylor, Clark, and Sinclair, 1990). The largest of these studies was conducted by Myers in the 1950's ( $n=5,355)$. Two extensive follow-ups were done with Myers' original data (Myers \& McCaulley, 1977). The research on type and medical specialties, that followed Myers' work, was done primarily in the area of family medicine.

Myers predicted that sensing types would be more attracted to primary care specialties because these specialties offer direct patient care which requires an ability to apply learned skills and knowledge in the practical issues of health-care delivery. She suggested that intuitives would be better suited for specialty fields on the cutting edge of 
development, offering diagnostic and treatment challenges (McCaulley, 1977). Her sample supported her prediction as general practitioners were overrepresented by Sensing, Thinking, Judging types (McCaulley, 1977).

In the 1970's there continued to be more Sensing and Judging type students choosing Family Practice. Quenk and Heffron (1975) used the MBTI to compare personality types of family practice residents and teachers. Sixty percent of Quenk and Heffron's combined sample of residents and teachers $(n=176)$ were Sensors, $40 \%$ were intuitives, $73 \%$ were judgers, and $27 \%$ were perceptives. The authors suggested that the passage of a few years would see a change in the types attracted to family practice as it was, and still is, a rapidly developing and changing field.

Freidman and Slatt (1988) studied medical students $(n=521)$ who entered medical school from 1978 through 1981 to determine if MBTI scores from the first year of medical school would predict choice of medical specialty in the postgraduate year. Their results, like earlier studies, found that students choosing family medicine tended to be sensing and judging types, though they did not offer specific percentages of each type. They also found that the $S / N, T / F$, and $J / P$ dimensions were statistically predictive of specialty choice (p.<.001).

Later research by Taylor, Clark, and Sinclair (1990) showed a shift in the types of students who chose family practice in the late 1980 's. Their results supported Quenk et al.'s earlier prediction that the field of family practice would attract different types as the field evolved. Taylor et al. used the MBTI to determine the personality types that were 
most common among family practice residents in the 1980's. They compared their sample ( $n=778)$, collected from 1984-1987, with two previous samples: Myers' sample of general practitioners $(n=1,010)$ in the 1950's and Quenk and Heffron's (1975) sample of family medicine residents and faculty $(n=176)$. They found that there was a dramatic increase in the number of intuitive/feeling types choosing family practice in the late 1980 's. Their sample contained $60 \%$ intuitives and $61 \%$ feeling types. As in the 50 's and 70 's, there continued to be more judging types than perceptive types.

Taylor et al. offered the following thoughts about their findings. They suggested that the field of general practice in the earlier decades offered predictable activities and routines, which would appeal to sensing types. They thought that Family Practice, after becoming an approved specialty in the 70 's, would attract more intuitives who would be attracted to a new specialty, on the cutting edge and offering new possibilities. They also suggested that the feeling types would be attracted to family practice because of its focus on behavioral science, patient care, and societal issues.

This study will build on previous studies by examining Loma Linda University medical students' personality types and choice of residency specialties to determine if there is a difference in the personality types of students who choose primary care residencies and those who choose specialty residencies in the 1990's. The 90's are a time of rapid change in health care delivery and primary care physicians will be key players in any new health plan policy (Health Security Act, 1993; Greer, 1994). 


\section{CHAPTER 3}

\section{METHODOLOGY}

\section{Hypothesis}

The Myers-Briggs Indicator measures preferences for gathering information and making decisions (Myers Manual, 1985). These preferences are significant in career choice (McCaulley and Myers, 1977) Based on previous research done with the MBTI in medical education, it is hypothesized that there will be a difference in personality type of Loma Linda students who choose primary care residencies rather than subspecialty residencies.

\section{Null Hypothesis}

It is hypothesized that there is no significant difference between personality types, as measured by the MBTI, between Loma Linda students who choose primary care residencies and those who choose subspecialty residencies.

\section{Sample}

The population was 309 Loma Linda University School of Medicine students in the classes of 1993 and 1994. The sample for this study $(\mathrm{N}=220)$ consisted of Loma Linda University School of Medicine students from the class of $1993(n=90)$ and the class of 
1994 ( $n=130$ ) who took the Myers Briggs Type Indicator in their freshman year, completed medical school, and matched with a residency program during the National Match Program held in March of the students' senior year of medical school. There were 146 males (66\%) and 74 females (34\%) in the sample.

\section{Instrumentation}

The instrument used in this study was the Myers-Briggs Type Indicator Form G. The MBTI is considered a well validated instrument (Coan, 1978; Murray, 1990; Thompson \& Borrello, 1986). Split-half and test-retest reliability for Form $\mathrm{G}$ have been generally satisfactory (Murray, 1984). According to Murray (1984, p. 1191), "group differences and correlations are broadly supportive of the construct validity of the M-B Indicator scales, indicating that the four scales measure important dimensions of personality that approximate those of Jung's typology theories." Form G contains 126 questions and is now considered the standard form of the MBTI (Murray, 1984).

\section{Data Collection}

Students entering Loma Linda University School of Medicine in the fall of years 1989 and 1990 were administered Form $\mathrm{G}$ of the MBTI. The instrument was administered on the first day of orientation by the Associate Dean of Student Affairs. Participation was voluntary. All students present took the indicator. The Associate Dean of Student Affairs made the data available. Information on students' choice of residency was accessed through the Office of Educational Affairs. Data were entered into SPSS software and analyzed. 


\section{Data Analysis}

The chi-square test was used to determine the relationship between medical students who chose primary care and those who chose subspecialty residencies by their MBTI type. Primary care specialties included family medicine, general internal medicine, and pediatrics. All other specialty choices were considered subspecialties.

Initial crosstab analysis of the 16 Myers-Briggs types and 2 residency specialty categories resulted in too many empty cells. A second chi-square analysis was conducted with four $2 \times 2$ tables representing each dimension (i.e. E/I, S/N, T/F, P/J) and the two areas of residency specialty choice. A third chi-square analysis was run with a $4 \times 2$ table using the combined preference for gathering information with the preference for making decisions (SF, ST, NF, NT) and the two areas of residency specialty choice. Finally, a $4 x$ 2 table was created using the SJ, SP, NT, and NF temperament dimensions described by Keirsey \& Bates (Keirsey \& Bates, 1978) and the two areas of residency specialty choice. 


\section{CHAPTER 4}

\section{RESULTS}

Chi square analyses were employed to determine relationships between the types of students who chose primary care residencies vs. subspecialty residencies and MBTI type.

Chi square analysis was first used to determine relationships between each dimension of the MBTI type and specialty choice. Previous research has found that the $\mathrm{S} / \mathrm{N}$ and $\mathrm{T} / \mathrm{F}$ preferences are important in choosing an occupational field, while the $\mathrm{E} / \mathrm{I}$ and $\mathrm{P} / \mathrm{J}$ preferences are important when choosing a specific area or work environment within a given occupational field (Hammer \& Macdaid, 1992). Of the four MBTI dimensions, only the Perceiving/Judging dimension was found to be statistically significant $X^{2}(1, \underline{N}=220)=$ $5.983, \mathfrak{p}<.01)$ for the primary care group and the subspecialty group. Sixty-nine percent of the sample were judging types and $31 \%$ were perceiving types. Of the perceiving types, $63 \%$ chose subspecialties. Of the judging types, $55 \%$ chose primary care. This finding was consistent with the literature. 
TABLE 1

PERCEIVING/JUDGING DIMENSION AND SPECIALTY CHOICE

$\begin{array}{llll} & \text { Perceiving } & \text { Judging } & \underline{\mathrm{N}} \\ \text { Primary Care } & 37 \% & 55 \% & 108 \\ \text { Subspecialty } & 63 \% & 45 \% & 112 \\ \text { N } & 68 & 152 & \end{array}$

Chi square analysis was then used to determine if there was a relationship between the combined preferences for gathering information and decision-making (SF, ST, NF, NT), which Myers found are important factors in career choice (Hammer \& Macdaid, 1992), and residency specialty choice $X^{2}(3, \underline{N}=220)=10.74, \underline{p}<.01$. This finding was consistent with the literature.

TABLE 2

\section{INFORMATION GATHERING/DECISION-MAKING DIMENSIONS AND SPECIALTY CHOICE}

Primary Care

Subspecialty

$\underline{N}$
ST

SF

$54 \%$

$46 \%$

78
NT

$32 \%$

$68 \%$

60
NF

$61 \%$

$39 \%$

46 
A review of Table 2 shows that of the four types, the NT's were more likely to choose subspecialty residencies (68\%) while NF's were most likely to choose primary care residencies $(61 \%)$.

In an effort to further investigate the relationship between type and specialty choice, chi square analysis was employed using Keirsey's temperament types (SP, SJ, NT, NF) and the two residency specialty categories $\left.X^{2}(3, \underline{N}=220)=15.684, \underline{p}<.001\right)$.

\section{TABLE 3}

TEMPERAMENT TYPE AND SPECIALTY CHOICE

SJ

SP

NT

$\mathrm{NF}$

$\underline{\mathrm{N}}$

Primary Care

Subspecialty

$\underline{N}$
$58 \%$

$42 \%$

90
$33 \%$

$67 \%$

24
$32 \%$

$68 \%$

60
$61 \%$

$39 \%$

46
108

220

A review of Table 3 shows that SJ's (58\%) were more like to choose primary care while SP's (67\%) were more likely to choose subspecialty residencies. 


\section{CHAPTER 5}

\section{DISCUSSION}

This sample was almost evenly divided between those who chose primary care residencies (49.1\%) and those who chose subspecialty residencies (50.1\%). All MBTI types were represented in the sample. Based on this sample, three areas of relationship between Myers Briggs Personality Type and residency choice were found to be significant: the perceptive/judging dimension, Myers' combined information gathering and decisionmaking preferences (ST, SF, NT, NF), and Keirsey's temperament types (SP, SJ, NT, and $\mathrm{NF})$.

There were more judging types in the total sample (69\%), and more judging types than perceiving types in both primary care $(n=83)$ and specialty categories $(n=69)$; however, a larger than expected number of judgers chose primary care (55\%). Primary care physicians often must make decisions based on limited information, and they form a diagnosis and therapeutic plan quickly. Their work days are fairly organized and predictable. These are activities that would appeal to the judging type as judging types prefer to follow schedules, and are orderly, organized, and systematic. They are more tolerant of routine procedures than the perceiving types and they enjoy making decisions quickly from the possibilities presented to them. 
When examining Myers' combined information gathering and decision making preference, it was found that NT's were more likely to choose a subspecialty residency (68\%) while NF's were more likely to choose a primary care residency (61\%). The NT type logically preferred the subspecialties where they could use their talent for in-depth knowledge, complex analysis, and research. The NF type would be attracted to the human side of primary care. They would enjoy frequent patient contact, providing care to entire families, and dealing with psychosocial issues. They would bring personal warmth to each encounter.

Keirsey's SJ and SP temperaments showed the most variation in residency choice. This may be due to the fact that Myers' combined information gathering and decisionmaking functions are useful in making initial career decisions, while the perceiving/judging attitudes (which are reflected in the SJ and SP temperaments) have been found to be useful in selecting a career area within a given field (Hammer \& Macdaid, 1992).

SP's chose subspecialty residencies more often than expected (67\%). This type prefers a varied work pattern with immediate rewards - conditions found more often in the subspecialties. They also enjoy using technical skills which are utilized more often in the procedures performed by subspecialists.

SJ's chose primary care residencies more often than expected (58\%). SJ's are motivated by the need to be useful and to serve society. While all physicians fill this role, Keirsey \& Bates (1978) note that the care of others is the special concern of the SJ. In 
addition, the primary care physician is often involved in community activities and is a visible pillar of society. This role would appeal to the SJ temperament.

When comparing this sample to Myer's sample of medical students in the 1950's (thinking 54\% -judging 47\%), the Loma Linda University sample had more thinking (62.7\%) and judging types (69.1\%). The type that was least attracted to medicine in the 1950's were the ESTJ's, which Myers described as the business type (Myers \& Myers, 1980). An interesting finding was that, in this sample, ISTJ's were the largest group (17.3\%) followed by ESTJ's (11.4\%). This suggests a shift from a humanitarian or scientific viewpoint of medicine to an emphasis on the business and financial aspects of medicine. This may reflect students' awareness of the managed care environment in medicine, or may reflect how the physician is currently portrayed in society.

A number of studies have been conducted in the area of personality type of family medicine residents (McCaulley, 1977; Quenk, 1975; Taylor, 1990). This sample, similar to previous samples, found a greater percentage of judging types in family medicine. This sample also found a greater percentage of thinking/sensing types in family medicine, a finding consistent with Myers and Quenk's research of the 50's and 70's.

These findings may indicate that the types of students who are choosing primary care residencies in the 1990's may be oriented towards the business aspects of medicine. This trait will be useful for those working in the managed care environment. Forty-one percent of Loma Linda University's total sample were the SJ type. The SJ's in this sample chose 
primary care residencies (58\%) more often than subspecialties (42\%). This may bode well for increasing the number of students who choose primary care residencies.

The NF's made up only $20 \%$ of the total sample and $61 \%$ of them chose primary care. These physicians will be able to provide empathic primary care with excellent communication skills, but may need to receive additional training in the area of practice management in order to work effectively in the managed care arena.

This study was useful in providing data to Loma Linda University's School of Medicine about the type composition of its medical students; however, the implications of the study to other institutions are limited. This small sample represents one private school, located in California, where more than $70 \%$ of the insured population receives some type of managed care (Directory of Managed Health Care, 1993). These factors make this a unique sample.

Another limiting factor is that this study looked at choice of residency: a follow-up study would need to be conducted to determine if students complete their chosen residency or change career paths. In addition, only $66 \%$ of students who choose primary care residencies are expected to become practicing primary care physicians (Family Practice Update, May 11, 1995).

Although the findings of this study cannot be applied broadly, the process of conducting the study provided this author with the opportunity to gain in-depth knowledge of the MBTI and its practical uses and limitations in career counseling. 


\section{CHAPTER 6}

\section{SUMMARY, CONCLUSIONS, AND RECOMMENDATIONS}

\section{$\underline{\text { Summary }}$}

The hypothesis of this study was that Loma Linda University medical students who chose primary care residencies would have different Myers-Briggs personality types than those students who chose subspecialty residencies. The Associate Dean of Student Affairs had collected MBTI data on incoming freshman from the Classes of 1993 and 1994. Information on the residency specialties students entered was obtained from the Office of Educational Affairs.

Three chi-square analysis were run on the sample of 220 students. First, each dimension of the MBTI (E/I, S/N, T/F, P/J) was examined in relation to the two residency specialty choice groups. It was found that the $\mathrm{P} / \mathrm{J}$ dimension was significant with more of the Judgers choosing primary care residencies (55\%) and more of the Perceivers choosing subspecialty residencies $(63 \%)$.

The second analysis examined the combined information-gathering/decision-making dimensions of the MBTI (ST, SF, NT, NF). The ST's and SF's were slightly more likely to choose primary care residencies ( $54 \%$ and $53 \%$ ). NF's were also more likely to choose primary care $(61 \%)$ while the NT's preferred subspecialty residencies $(68 \%)$. 
The third analysis examined the Keirsey temperament types (SJ, SP, NT, NF) and residency choice. The NT and NF's have been discussed previously. The SJ's were more likely to choose primary care residencies (58\%) while the SP's were more likely to choose subspecialty residencies (67\%).

\section{Conclusions}

This study, like most previous research found that the personality types of students who chose primary care residencies were more likely to be sensing, thinking, and judging types (Friedman and Slatt, 1988; Myers and McCaulley, 1977; Quenk and Heffron, 1975). This type would be effective in working in a managed care environment; however, they will also require training in communication and "people-skills" in order to give empathic patient care.

The findings and predictions of this study differed from those of Taylor et al.'s (Taylor, Clark and Sinclair, 1990). They found more intuitive/feeling types in family medicine and predicted that this pattern would continue in family medicine. One reason for the shift back to the more practical, business-like personality in primary care may be the increased presence of managed care in the health care environment.

The findings of this research can be applied in counseling students about medical career choices. In a 1993 survey of 114 students, Hesser et al. found that 59\% of medical students experience difficulty in choosing a medical specialty and $43 \%$ of their medical schools did not provide assistance to students having difficulty in choosing a specialty. This author plans to offer career guidance to students, using the Myers Briggs Type 
Inventory in conjunction with the Glaxo Pathway Program (Glaxo, 1992). The Glaxo Pathway Program provides students with specific information about the various specialties and offers them guidelines for gathering information and making decisions.

Students who learn about their personality type may gain a better understanding of how they prefer to gather information and make decisions related to specialty choice. The extraverts may prefer to talk to a number of physicians from a variety of specialties while the introverts may prefer to watch taped interviews or read about the various specialties. The judging types may feel anxiety during the information gathering process and may rush to a decision while the perceiving types may prefer to postpone the decision for as long as possible. A career counselor can help the student become aware of these tendencies.

The findings of this study reinforced previous findings that the sensing/judging types are more likely to choose primary care specialties over the subspecialites. This finding can be applied to the career counseling setting by letting students know that while all personality types are represented in medicine and all types can bring their talents to the specialty they choose, more sensing/judging types tend to choose primary care while more intuitive/perceptive types tend to choose subspecialties. This knowledge could lead to a discussion of the differences between the two categories of specialties and assist students in their process of narrowing down choices.

Loma Linda University Medical Center is a tertiary care facility providing hightechnology care such as heart transplants for babies and a proton accelerator for the treatment of cancer. Because of this emphasis on the latest technological advances in 
medicine, students may receive the message that the best students should enter highly specialized fields. Primary care specialities are often viewed by subspecialists as less desirable and as a second choice for those students who can't "make it" in the subspecialites. This research found that sensing/judging types tend to select primary care more often than subspecialties; therefore, a student of this type could be counseled that many others of their type choose primary care specialties. This finding may encourage them to explore the choices in primary care.

While the MBTI has been found to be useful in career counseling, this author has learned never to counsel a student against a particular career because of their type. It will be important to emphasize that type is only one factor to consider in choosing a specialty other factors such as location and lifestyle issues are also important. By using the MyersBriggs Type Indicator in conjunction with the Glaxo program, a broad range of career decision-making issues can be discussed.

\section{Recommendations}

There is, and will continue to be a growing demand for primary care physicians. Therefore, career counselors in medical schools should use all the tools available to them to provide students with information about residency selection and primary care specialties. Further research will be done at Loma Linda University to determine if the students in this sample remained in the specialty they chose for their residency. A followup survey may also be done a few years after the members of this sample are into their careers to determine career satisfaction. 
Future research should be conducted to determine if managed care has an effect on the personality types that enter medical schools. This research could have implications in areas of patient satisfaction with their physicians and physician satisfaction with their careers. 


\section{BIBLIOGRAPHY}

Alper, P.R. (1994). Primary care in transition. Journal of the American Medical Association, 272, 1523-1527.

Cohen, J. J., Bowman, M. A., DeAngelis, C., Dickler, R. M., Fallon, H. J., Farrar, J. Friedmann, P., Graham, D., Hellman, S., Johnson, R. B., King, Sheldon, Massad, R., Skelton, W. D., Stoeckle, J., Wilson, E. A., \& Zender, B. (1993). AAMC policy on the generalist physician. Academic Medicine, 68, 1-6.

Clawson, D. K. (1990). The education of the physician. Academic Medicine, $65,84-88$.

Dial, T. H., \& Lindley, D. W. (1987). Predictive validity of specialty choice data from AAMC graduation questionnaire. Journal of Medical Education, 62, 955-958.

Directory of Managed Health Care. The American Managed Care and Review Association, 1993.

Family Practice Update. The Amercian Academy of Family Physicians, May 11, 1995. Kansas City, MO

Friedman, C. P., \& Slatt, L. M. (1988). New results relating the Myers-Briggs Type Indicator and medical specialty choice. Journal of Medical Education, 63, 325-327.

Greer, D. S. , Bhak, K. N., \& Zenker, B. M. (1994). Comments on the AAMC policy statement recommending strategies for increasing the production of generalist physicians. Academic Medicine, $\underline{69}, 245-60$.

Hammer, A.L., \& Macdaid, G.P. (1992). MBTI Career Report Manual, Consulting Psychologists Press, Inc., Palo Alto, CA.

Hesser, A., Mehaffey, M., Thompson, M. (1995). Need for More Career Counseling. Academic Medicine, 70, 1.

Iglehart, J.K. (1994). Physicians and the growth of managed care. The New England Journal of Medicine, $331,1167-1171$.

Keirsey, D. \& Bates, M. (1978). Please Understand Me: Character \& Temperment Types, Prometheus Nemesis Book Co., Del Mar, CA 
McCaulley, M.H. (1977). The Myers longitudinal medical study. Monograph II, Department of Health, Education, and Welfare.

McCaulley, M. H. (1978). Application of the Myers-Briggs Type Indicator to medicine and other health professions. Monograph I, Washington, D.C.: U.S. Department of Health, Education, and Welfare.

Mitchell, W. D. (1975). Medical student career choice: a conceptualization. Social Science \& Medicine, 9 , 641-653.

Murray, J. B. (1990). Review of research on the Myers-Briggs Type Indicator. Perceptual and Motor Skills, 70, 1187-1202.

Myers, I. B. \& McCaulley, M. H. (1985). Manual for the Myers-Briggs Type Indicator: A guide to the development and use of the MBTI. Gainesville, Fl: Center for Applications of Psychological Type, 12-14.

Myers, I.B. \& Myers, P.B. (1993). Gifts Differing: Understanding Personality Type, Consulting Psychologists Press, Palo Alto, CA.

Otis, G. D., Weiss \& J. R. (1973). Patterns of medical career preference. Journal of Medical Education, 48, 1116-1123.

Petersdorf, R. G. (1993). The doctor is in. Academic Medicine, 68, 113-117.

Quenk, N., \& Heffron, W.A. (1975). Types of family practice teachers and residents: a comparative study. Journal of Family Practice, 2 , 195-200.

Taylor, A. D., Clark, C., \& Sinclair, A. E. (1990). Personality types of family practice residents in the 1980s. Academic Medicine, $. \underline{65}, 216-218$.

The President's health security plan: the Clinton blueprint. The White House Domestic Policy Council. Times Books, Division of Random House, NY. 139-143.

Thompson, B. \& Borrello, G. (1986). Construct validity of the Myers-Briggs Type Indicator. Educational and Psychological Measurement, 46, 745-752.

Weil, P. A. \& Schleiter, M. K. (1981). National study of internal medicine manpower: vi. Factors predicting preferences of residents for careers in primary care or subspecialty care and clinical practice or academic medicine. Annals of Internal Medicine, 94, 691-703. 
Zeldow, P. B., \& Daugherty, S. R. (1991). Personality profiles and specialty choices of students from two medical school classes. Academic Medicine, 66, 283-287. 